\title{
Undercooling studies on dispersed bismuth droplets
}

\author{
SANJAY CHAUBEY, VAKIL SINGH and P RAMACHANDRARAO* \\ Department of Metallurgical Engineering. *School of Materials Science and Technology, \\ Institute of Technology, Banaras Hindu University, Varanasi 221005 , India \\ MS received 18 April 1987; revised 2 July 1987

\begin{abstract}
In the zinc-bismuth system, a monotectic reaction occurs at $689 \mathrm{~K}$ and 0.6 at.\% Bi composition. Rapid solidification of the as-cast monotectic alloy led to a micromorphology in which bismuth was uniformly and bimodally distributed as small droplets in the zinc matrix. Statistical analysis of the electron micrographs obtained from different transparent regions of the foils revealed that the size of most of the droplets was about $6 \mathrm{~nm}$. These droplets undercooled by $132 \mathrm{~K}$. An analysis of the nucleation rate measurements shows that the activation energy barrier to nucleation is of the order of $39.8 \mathrm{kcal} / \mathrm{mol}$ at the maximum undercooling.
\end{abstract}

Keywords. Undercooling; nucleation; bismuth.

\section{Introduction}

The phenomenon of undercooling exhibited by liquid metals and alloys below their thermodynamic freezing temperature has been given due importance by materials scientists. Heterogeneities present within the bulk melt usually initiate crystal nucleation at low undercooling. However, various experimental techniques for extending the limit of undercooling are now available (Vonnegut 1948; Turnbull 1950; Duwez et al 1960; Southin and Chadwick 1978; Lacy et al 1981). The droplet dispersal technique proposed by Vonnegut (1948) and later employed by Turnbull $(1950,1952)$ and coworkers (Turnbull and Cech 1950) is an effective technique for extending the range of observable undercooling. One of the useful techniques for inducing large undercooling in bulk melts is the glass slag technique in which the melt is under the cover of a fluid glass slag in a crucible (Fehling and Scheil 1962). By repeated melting and freezing under the glass flux, drastic undercooling is achieved in the melt. An emulsification technique in which the droplets are supported in aromatic oils and stabilized by reaction with organic peroxides and organic acid modifiers was developed by Rasmussen and Loper (1975). Such an emulsification procedure segregates heterogeneities present in the bulk melt into a small fraction of the droplet population and permits measurement of the undercooling in the presence of different types of surface layers. Southin and Chadwick (1978) employed the so-called liquidentrapment technique, described previously by Wang and Smith (1950), for the enhancement of the degree of undercooling. Binary eutectic or monotectic alloy systems are best suited for this technique. The composition of the alloy is adjusted such that the equilibrium structure contains a small fraction of either one of the monotectic phases or the eutectic mixture. Subsequent annealing, at temperatures between the solidus and liquidus of the alloy, for sufficient time leads to the formation of droplets within the solid matrix grains. Such isolated droplets, free from heterogeneities, undercool enormously and can even produce metastable phases (Ramachandrarao et al 1979). In monotectic alloy systems isolated droplets of the 
second phase can also be produced through the process of rapid solidification (Chattopadhyay and Ramachandrarao 1980).

In the present study, the conventional gun-technique of rapid solidification is employed for the formation of isolated bismuth droplets in zinc matrix. The undercooling behaviour of such entrapped droplets has been characterized and discussed in the light of earlier work and the available models for heterogeneous nucleation of melts.

\section{Experimental}

$\mathrm{Zn}-0.6$ at. \% Bi monotectic alloy and $\mathrm{Zn}-9.69$ at.\% Bi hypermonotectic alloy were prepared by melting the accurately weighed components together in a graphite crucible under an argon atmosphere. The alloys were made from $5 \mathrm{~N}$ purity metals. The alloy melt was vigorously shaken and then it was allowed to solidify in the crucible under an argon gas cover.

Small alloy pieces weighing approximately $20 \mathrm{mg}$ were cut from the bulk alloy and were rapidly solidified using the gun-technique in order to disperse $\mathrm{Bi}$ in the $\mathrm{Zn}$ matrix in the form of small droplets. The resultant product was in the form of irregular foils, which were transparent in many places to the electron beam. Electron microscopy of the foils was carried out and the micrographs were analyzed to arrive at the statistical size distribution of Bi droplets.

Using a differential scanning calorimeter (Perkin Elmer DSC II) and about $10 \mathrm{mg}$ of the rapidly solidified foils, thermograms were recorded at heating and cooling rates of $2.5 \mathrm{~K} / \mathrm{min}$ to study the undercooling behaviour and nucleation kinetics of $\mathrm{Bi}$ droplets. The lower and upper temperature limits of the DSC II were set at $323 \mathrm{~K}$ and $570 \mathrm{~K}$ respectively. In every run empty $\mathrm{Al}$ sample pan with cover served as a reference. Argon gas was used for purging throughout the experiment.

\section{Results}

Statistical analysis of electron micrographs obtained from different transparent regions of the foils reveals that the size of most of the Bi droplets is of the order of $6 \mathrm{~nm}$ (figure 1). However, in thicker sections some bigger droplets were also seen in the micrographs but they were few in number. The size of the bigger droplets was not less than $25 \mathrm{~nm}$. In thin sections of the rapidly solidified product fine scale distribution was observed, whereas in thicker sections a bimodal distribution consisting of coarse as well as fine particles was observed. A typical micrograph is shown in figure 2(a, b). Several of the big Bi particles show faceting (figure $2 b$ ).

Undercooling behaviour restricted to well-defined exothermic crystallization events is illustrated in figures 3-6. Figures 3 and 4 present DSC thermograms for rapidly solidified $\mathrm{Zn}-0.6$ at. \% $\mathrm{Bi}$ and $\mathrm{Zn}-9.69$ at.\% $\mathrm{Bi}$ respectively. Figures 5 and 6 present DSC thermograms for as-cast $\mathrm{Zn}-0.6$ at. $\% \mathrm{Bi}$ and $\mathrm{Zn}-9.69$ at. $\% \mathrm{Bi}$ respectively. The melting temperature, $T_{L}$, recorded in the thermograms of figures 3-6 is $528 \pm 1 \mathrm{~K}$ which simply represents the melting of Bi-rich droplets entrapped in $\mathrm{Zn}$ matrix. Apart from this melting transition at $528 \mathrm{~K}$ one more small endothermic transition appears at $\sim 440 \mathrm{~K}$. By successive heating and cooling of the sample the area under the peak appearing at $440 \mathrm{~K}$ increases slightly. After the third cycle there 


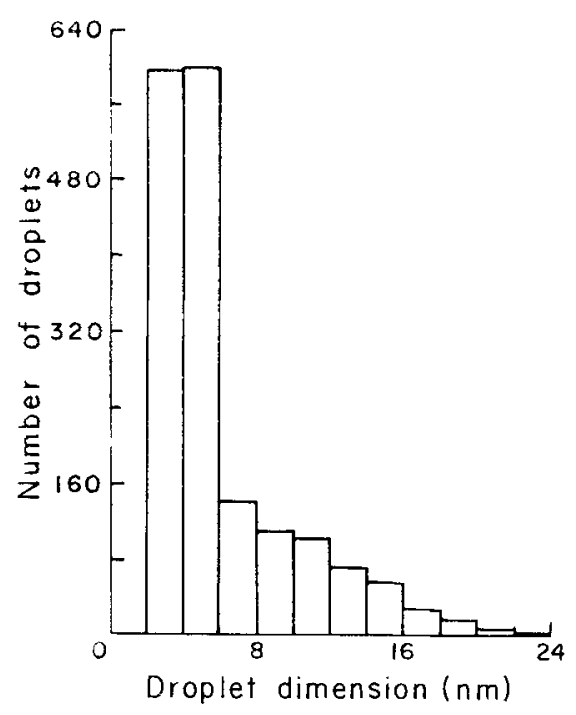

Figure 1. Histogram showing the droplet size distribution.

is an almost negligible increase in the area. Cooling thermograms in figures 3 and 4 show a number of exothermic peaks, the last one appearing at 397-396 K. The largest undercooling achieved is $132 \mathrm{~K}$ which is equivalent to about $0.25 T_{L}$, where $T_{L}$ is the liquidus temperature. Several experiments have shown that the number and position of exothermic peaks change. However, the position of last exothermic peak appearing at $397 \mathrm{~K}$ remains unchanged. Thermograms of figures 5 and 6 have been recorded for comparing the behaviour of rapidly solidified foils with the as-cast ones. As in figures 3 and 4, thermograms of figures 5 and 6 also show a number of exothermic peaks, the last one appearing at 398-397 K. As far as the highest degree of undercooling is concerned it is of the same order of magnitude as in the case of its rapidly solidified counterpart. Except for the last peak occurring at $397 \mathrm{~K}$, the number and the position of other exothermic peaks change from sample to sample.

\section{Discussion}

The experimental results obtained in this work clearly show that crystallization of Bi-rich droplets entrapped in Zn-matrix occurs through several nucleation events. It is worthwhile to note that there is a close resemblance between the observations on slowly cooled samples of as-cast and rapidly solidified $\mathrm{Zn}-\mathrm{Bi}$ alloys. Rapid solidification possibly restricts the layering mechanism in liquid monotectic alloys and results in granulation of Bi (Chattopadhyay and Ramachandrarao 1980). These granules or droplets are distributed on a coarse scale in thicker portion whereas fine scale distribution is observed in thin portion of the rapidly solidified product. Most of the active nucleants which are responsible for lesser undercoolings are restricted to within bigger and coarser droplets leaving the finer ones relatively free. A number of exothermic peaks at different temperatures indicate the presence of different types of heterogeneities, each becoming effective at different undercoolings.

Bulk samples of $\mathrm{Bi}$ were undercooled more than $60^{\circ}$ when melted in a flux of 


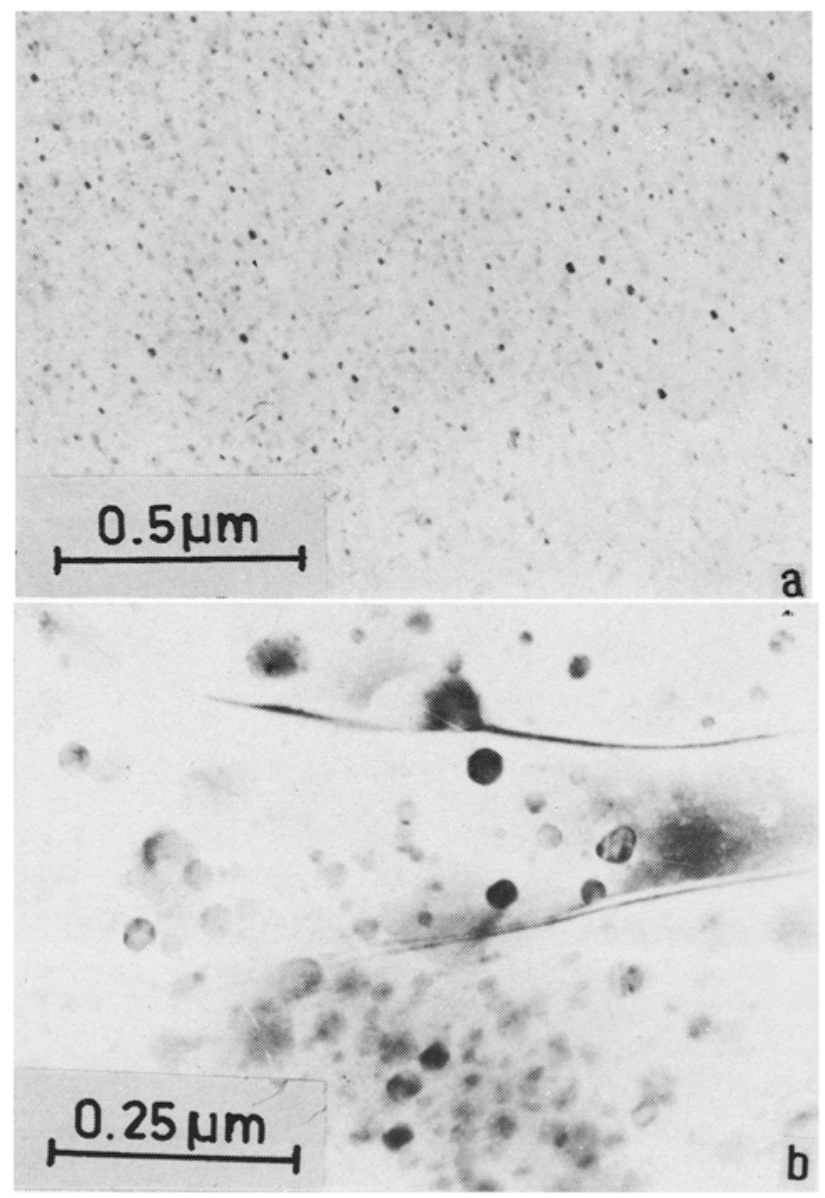

Figure 2. Electron micrographs showing dispersion of $\mathrm{Br}$ particles. a. fine scale distribution and b. bimodal distribution.

$\mathrm{SnCl}_{2}+\mathrm{ZnCl}_{2}$ (Bosio et al 1961). The maximum recorded undercooling, $\Delta T=132$, is greater than the value reported by Turnbull and Cech (1950) which is $90^{\circ}$, but is less than the value reported by Perepezko (1984) which is $227^{\circ}$. According to Turnbull and Cech (1950) homogeneous nucleation for any metal was said to occur at approximately $0.2 T_{L}, T_{L}$ being the melting temperature. However, this limit does not seem to be appropriate. The substantial undercooling recorded in the present investigation may be understood as a consequence of surface catalytic effect and implies that the $\mathrm{Zn}$-matrix containing $\mathrm{Bi}$ dispersion provides a suitable surface for catalyzing the nucleation of fine $\mathrm{Bi}$ droplets which are supposed to be relatively free from heterogeneities. The nucleation events occurring at lesser undercoolings are also heterogeneous in nature but impurity-aided. Fine $\mathrm{Bi}$ droplets exhibiting larger undercooling are clean and are in contact with only solid $\mathrm{Zn}$ surface. Therefore, it is appropriate to call the responsible nucleation process as clean heterogeneous nucleation (Southin and Chadwick 1978). The unspecified surface layer formed during emulsification in the experiments of Perepezko (1984) is less catalytic than the 


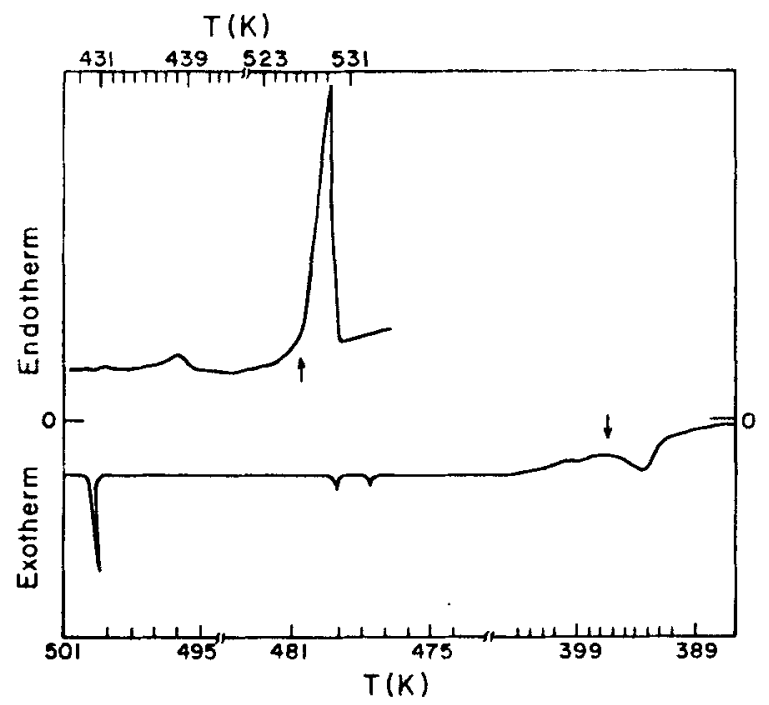

Figure 3. Thermogram for rapidly solidified $\mathrm{Zn}-0.6 \mathrm{at} . \%$ Bi recorded the heating and cooling rates of $2.5 \mathrm{~K} \mathrm{~min}^{-1}$. The transformation temperatures are marked by an arrow.

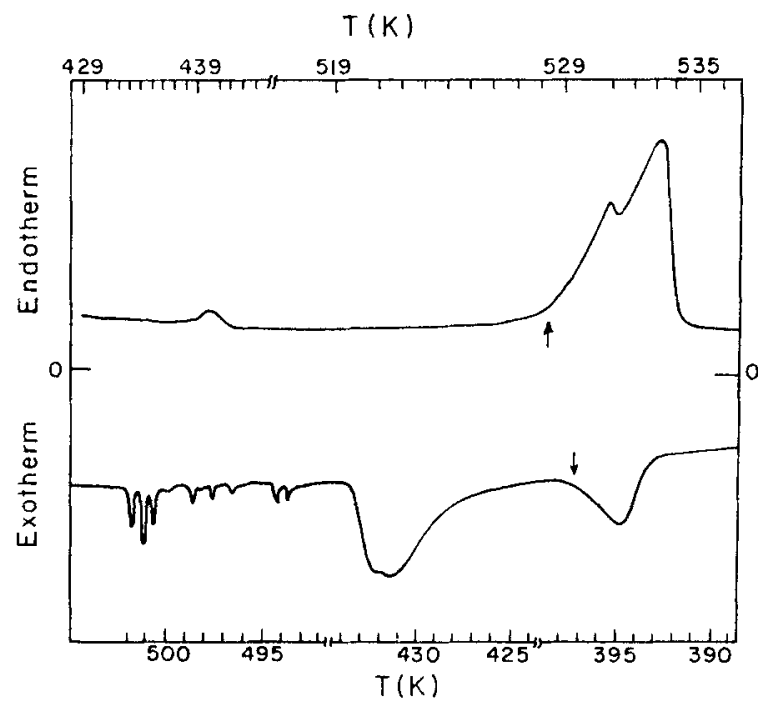

Figure 4. Thermogram for rapidly solidified $\mathrm{Zn}-9.69$ at. $\%$ Bi recorded at the heating and cooling rates of $2.5 \mathrm{~K} \mathrm{~min}^{-1}$. The transformation temperatures are marked by an arrow.

solid $\mathrm{Zn}$ surface of the present case and hence results in the highest level of undercooling for Bi reported till date.

The observation of the endothermic transition at $528 \pm 1 \mathrm{~K}$ in the case of as-cast as well as rapidly solidified product of the $\mathrm{Zn}$ - $\mathrm{Bi}$ alloy is in accord with the phase diagram of $\mathrm{Zn}-\mathrm{Bi}$ system (Hansen 1958). A notable feature observed in the thermograms of figures 3-6 is the appearance of one more endothermic transition at $440 \mathrm{~K}$. This temperature did not correspond to the melting points of oxides of bismuth 


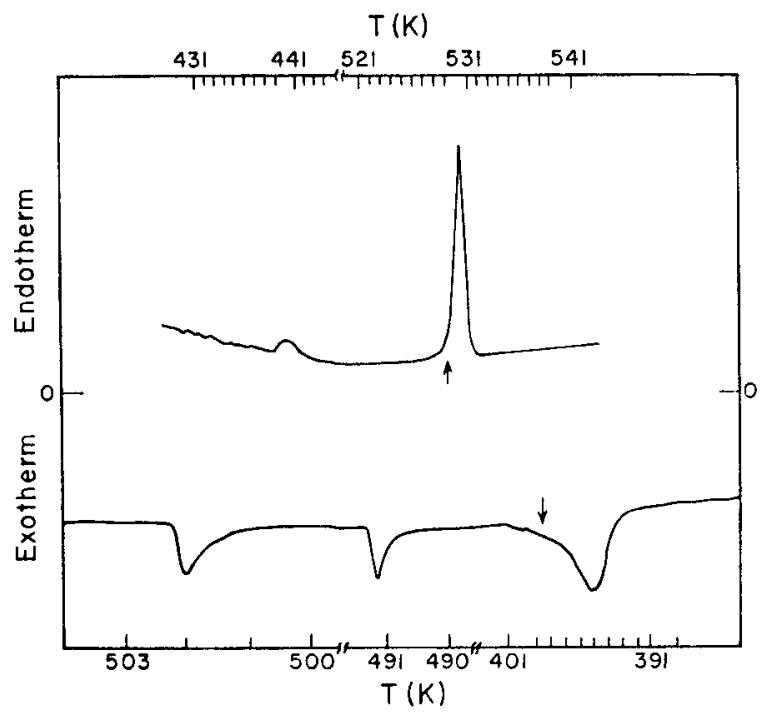

Figure 5. Thermogram for the as-cast $\mathrm{Zn}-0.6 \mathrm{at} \% \mathrm{Bi}$ recorded at the heating and cooling rates of $2.5 \mathrm{~K} \mathrm{~min}^{-1}$. The transformation temperatures are marked by an arrow.

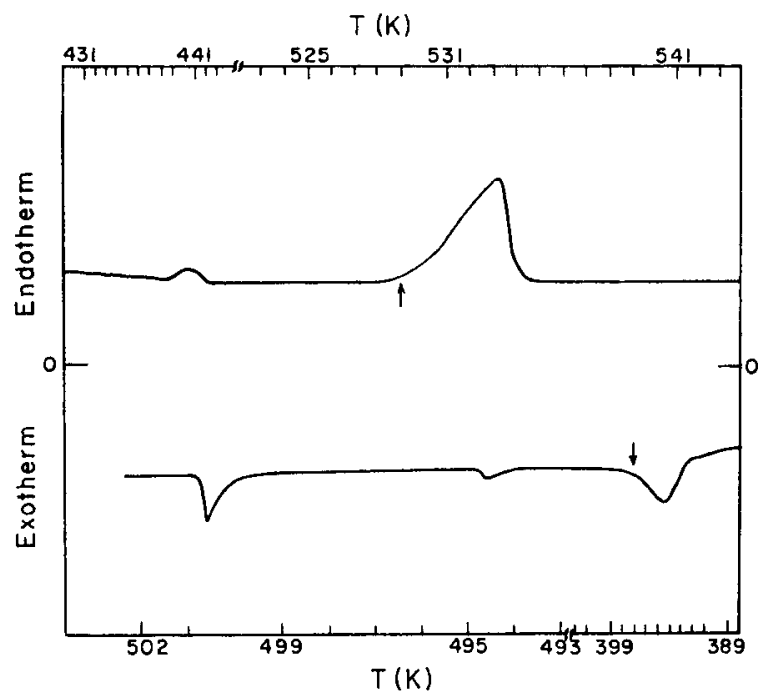

Figure 6. Thermogram for the as-cast $\mathrm{Zn}-9.69$ at. $\%$ Bi recorded at the heating and cooling rates of $2.5 \mathrm{~K} \mathrm{~min}^{-1}$. The transformation temperatures are marked by an arrow.

(Weast 1977) and so the presence of any oxide of bismuth was ruled out. However, Bi is reported to undergo several polymorphic transformations (Perepezko 1980). A clear inspection of the areas under the two melting transitions indicates that the volume fraction of the phase appearing at $440 \mathrm{~K}$ is less than $5 \%$ of the total. X-ray diffraction studies did not give a clear evidence for the presence of a polymorph of $\mathrm{Bi}$. However, it may not be possible to detect any polymorph by X-ray diffraction since the volume fraction of the phase is too small. Perepezko (1980) has already suggested 
that at high undercooling solidification is mitrated by the nucleation of $\mathrm{Bi}$ with different crystal structures. For the additional endotherm observed at $447 \mathrm{~K}$ he argued that the structural modification may be the $\mathrm{Bi}$ (II) phase.

If it is assumed that only one nucleation event per droplet is enough for solidification of each fine droplet, the heat released for a droplet solidification in a DSC will be the same as for any other droplet and hence the amount of heat released is a direct measure of the number of droplets to solidify. Following the base line correction employed by earlier workers (Scott and Ramachandrarao 1977) the total area under the cooling thermogram from any time $t_{1}, A_{t_{1}}$ gives a measure of the number of droplets unsolidified at time $t_{1}, N_{t_{1}}$. After a short interval of time $\Delta t$, the area left, $A_{t_{1}+\Delta t}$, is a measure of the number of droplets still unsolidified. $N_{1_{1}+\Delta t}$. In a constant cooling experiment it has been shown that the nucleation rate per droplet during a small time interval $\Delta t$ is (Wood and Walton 1970; Rasmussen and Loper 1976)

$$
J_{s}=-\frac{1}{\Delta t} \ln \left(-\frac{A_{i_{1}}+\Delta t}{A_{i_{1}}}\right) .
$$

The nucleation rate thus calculated corresponds to some average temperature of the sample during the time interval $\Delta t$. Because of slow cooling rate, sample temperature does not change appreciably over the time interval $\Delta t$. The nucleation rate per droplet, $J_{s}$, where $s$ is the average droplet surface area, has been calculated for thermograms recorded at a cooling rate of $2.5 \mathrm{~K} / \mathrm{min}$.

In the approximation of a spherical nucleus the temperature dependence of the nucleation rate for the constant cooling experiment is given by the expression (Turnbull 1952)

$$
J=A \exp \left(-\Delta G^{*} / k T\right)
$$

where $\Delta G^{*}$ is the thermodynamic barrier to nucleation and $A$ is a factor which is practically insensitive to small changes of temperature. For heterogeneous nucleation process $A$ is of the order of $10^{25 \pm 1} \mathrm{sec}^{-1} \mathrm{~cm}^{-2}$, whereas for homogeneous nucleation it is of the order of $10^{33 \pm 1} \mathrm{sec}^{-1} \mathrm{~cm}^{-3}$ (Turnbull 1950). For the homogeneous nucleation process

$$
\Delta G^{*}=16 \pi \sigma^{3} / 3 \Delta G_{r}^{2}
$$

For the heterogeneous nucleation process

$$
\Delta G^{*}=\frac{16 \pi \sigma^{3}}{3 \Delta G_{r}^{2}} f(\theta)
$$

where $f(\theta)={ }_{4}^{1}\left(2-3 \cos \left(\theta+\cos ^{3} \theta\right), \theta\right.$ being the contact angle. $\sigma$ and $\Delta G_{r}$ in (3) and (4) are solid-liquid interfacial tension and volume free energy change during crystallization respectively.

Recently Lele ef al (1985) developed the following novel expression for $\Delta G$ accompanying crystallization of an undercooled melt

$$
\Delta G=\Delta S_{j} \Delta T-\left[\Delta C_{p j} \Delta T^{2} /\left(T_{f}+T\right)\right] .
$$


Table 1. Comparison between the observed and calculated $\Delta G$; values for undercooled liquid bismuth.

\begin{tabular}{lccc}
\hline & $\Delta T$ & $\begin{array}{c}\Delta G(\mathrm{Bi}) \text { (Olesinski } \\
\text { and Abbaschian) } \\
(\mathrm{cal} / \mathrm{mol})\end{array}$ & $\begin{array}{c}\Delta G(\mathrm{Bi}) \\
\text { (Lele } \text { et al 1985) } \\
(\mathrm{cal} / \mathrm{mol})\end{array}$ \\
\hline 514 & 30 & 148 & 148 \\
499 & 45 & 222 & 223 \\
484 & 60 & 295 & 297 \\
469 & 75 & 367 & 371 \\
454 & 90 & 441 & 445 \\
439 & 105 & 513 & 518 \\
424 & 120 & 585 & 592 \\
409 & 135 & 656 & 666 \\
394 & 150 & 726 & 739 \\
\hline
\end{tabular}

$$
c^{-1}=\frac{1}{T \Delta T^{2}\left(1-\frac{\Delta C_{p f}}{\Delta S_{f}} \frac{\Delta T}{T_{f}+T}\right)^{2}}
$$

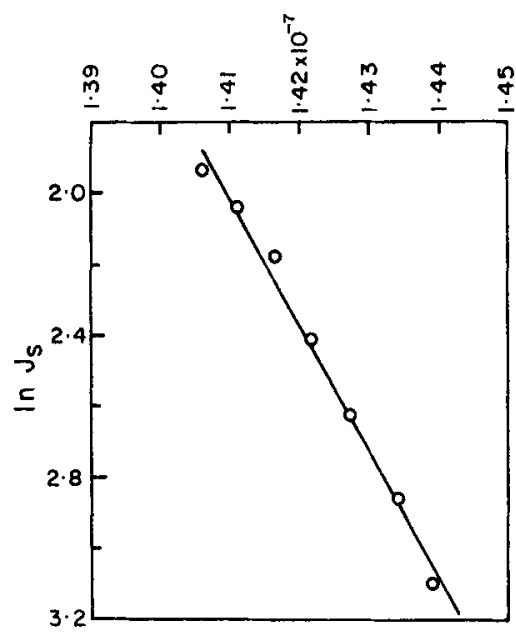

Figure 7. Temperature dependence of the nucleation rate.

$\Delta S_{f}$ and $\Delta C_{p f}$ in the above equation are entropy and heat capacity differences between the liquid and solid at the melting point. Suitability of the above equation has been checked with the help of an analytical equation for the Gibbs-free energy change for $\mathrm{Bi}$ which is written as (Olesinski and Abbaschian 1986)

$$
\begin{aligned}
\Delta G(\mathrm{Bi})= & 4198+108.96 T+15.234 \times 10^{-3} T^{2} \\
& -19.9493 T \ln T+2.05 \times 10^{5} T^{-1} \mathrm{~J} / \mathrm{mol} .
\end{aligned}
$$

Table 1 shows the comparison between the $\Delta G$ values calculated using (5) and (6) separately. From table 1 it is clear that even at higher undercoolings the agreement between both the values is quite satisfactory.

Combining (2), (4) and (5) we have the following expression for the heterogeneous 
nucleation process

$$
J=A \exp \left[-\frac{16 \pi \sigma^{3} f(\theta)}{3 k \Delta S_{f}^{2} C}\right]
$$

where $\quad C=T \Delta T^{2}\left[\frac{\Delta C_{p f}}{\Delta S_{f}} \cdot \frac{\Delta T}{\left(T_{f}+T\right)}\right]^{2}$.

From (7) it is clear that there must be a linear relationship between $\ln J$ and $C^{-1}$. Values of $\ln J_{s}$ calculated using (1) have been plotted against the temperature function, $C^{-1}$, in figure (7). As expected, a linear behaviour is observed over a range of the long tail on the thermogram which enabled us to arrive at the value of $39.8 \mathrm{kcal} / \mathrm{mol}$ for $\Delta G^{*}$.

The present study shows that a reduction in the size of the droplets alone is not a sufficient requirement for enhancing the degree of undercooling in the present technique. The undercooling achieved is strongly dependent on the surface activity of the matrix entrapping the droplet. Experiments on Bi suspended in other matrices by a similar technique will throw further light on the inherent undercooling tendency of Bi.

\section{Acknowledgements}

The authors gratefully acknowledge the helpful discussions they had with their colleagues Prof, S Lele and Dr K S Dubey. They also acknowledge with thanks the experimental facilities extended by Prof. S Ranganathan and the assistance rendered by Dr K Chattopadhyay.

\section{References}

Bosio L, Defrain A and Ebelboin L 1961 Compt. Rand. 2532343

Chattopadhyay K and Ramachandrarao P 1980 J. Mater. Sci. 15685

Duwez P, Willens R H and Klement W $1960 J$. Appl. Phys. 311136

Fehling J and Scheil E 1962 Z. Metallkde. 53593

Hansen P M 1958 Constitution of binary alloys (New York: McGraw Hill)

Lacy L L, Robinson M B and Rathz T J 1981 J. Cryst. Growth 5147

Lele S. Dubey K S and Ramachandrarao P 1985 Curr. Sci. 54994

Olesinski R W and Abbaschian G J 1986 Bull. Alloy. Phase Diagrams 7535

Perepezko J H 1980 in: Rapid solidification processings: principles and technologies Proc. Second Int. Conf., (eds) R Mehrabian, B H Kear and M Cohen (Virginia: Claitor`s Publishing Division) p. 56

Perepezko J H 1984 Mater. Sci. Eng. 65125

Ramachandrarao P, Lal K, Singh A Deo and Chattopadhyay K 1979 Mater. Sci. Eng. 41259

Rasmussen D H and Loper C R 1975 Acta. Metall. 231215

Rasmussen D H and Loper C R Jr 1976 Acta. Metall. 24117

Scott M G and Ramachandrarao P 1977 Mater. Sci. Eny. 29137

Southin R T and Chadwick G A 1978 Acta. Metall. 26223

Turnbull D 1950 J. Appl. Phys. 211022

Turnbull D 1952 J. Chem. Phys. 20411

Turnbull D and Cech R E 1950 J. Appl. Phys. 21804

Vonnegut B 1948 J. Colloid. Sci. 3563

Wang C C and Smith C S 1950 Trans. AIME 188136

Weast R C 1977 CRC handhook of chemistry and physics (Cleveland: CRC. Press) 58th Ed.

Wood G R and Walton A G 1970 J. Appl. Phys. 413027 